\title{
Raiva bovina segundo os mosaicos de uso e cobertura da terra no estado de São Paulo entre 1992 e 2003
}

\author{
[Cattle rabies according to the mosaics of land use and land cover in the state of Sao Paulo \\ from 1992 to 2003] \\ M.N. Gomes ${ }^{1}$, A.M.V. Monteiro ${ }^{2}$, M.I.S. Escada ${ }^{2}$ \\ ${ }^{1}$ Coordenadoria de Defesa Agropecuária do Estado de São Paulo \\ Rua Ministro Godoy, 310 \\ 05015-000 - São Paulo, SP \\ ${ }^{2}$ Instituto Nacional de Pesquisas Espaciais - São Paulo, SP
}

\begin{abstract}
RESUMO
O objetivo deste trabalho foi descrever a influência dos mosaicos de uso e de cobertura da terra na distribuição espacial da raiva bovina na região de maior incidência do Estado de São Paulo, entre 1992 e 2003. Geotecnologias foram utilizadas para gerar três camadas sobrepostas: a enfermidade caracterizada por uma função kernel, os tipos de uso e classes de cobertura da terra obtidos por classificação de imagens de satélites e a altitude. A enfermidade esteve fortemente moldada pelas áreas de vegetação rasteira (pastagens). O relevo pareceu formar os mosaicos de uso e cobertura da terra, os quais acabaram determinando os locais de grassamento ou não da enfermidade. Grandes áreas contínuas do mesmo tipo de uso e classe de cobertura da terra tenderam a ser protetoras da raiva bovina, ou favorecedoras em áreas vizinhas.
\end{abstract}

Palavras-chave: sensoriamento remoto, SIG, Desmodus rotundus, análise espacial

\section{ABSTRACT}

The influence of the mosaics of land use and land cover in the spatial distribution of cattle rabies was described in the major incidence region of the State of Sao Paulo, from 1992 to 2003. Geotechnologies were used to build three layers: the disease established by a kernel function, the land use and land cover obtained by satellite images classification, and the altitude. The disease was hardly shaped by grasslands. The relief seems to form the land use and land cover, which determine the regions for the occurrence or not of the disease. Large continuous areas of the same land use and land cover tend to be a protection to cattle rabies or to favor it in the neighborhood areas.

Keywords: remote sensing, GIS, Desmodus rotundus, spatial analyses

\section{INTRODUÇÃO}

A raiva bovina é uma zoonose causada por vírus do gênero Lyssavirus e transmitida principalmente pelo morcego hematófago Desmodus rotundus. Em virtude de sua relevância para as áreas da saúde pública, da ecologia e da economia (Mayen, 2004), essa enfermidade tem sido estudada, no intuito de identificar as influências da alteração do meio ambiente na sua difusão e as áreas prioritárias para o seu controle (Taddei et al., 1991; Kotait et al., 1998; Ministério..., 2005).

Silva et al. (2001), em estudo baseado no censo agropecuário e com dados agregados à malha municipal, consideraram que a raiva bovina no estado de Minas Gerais sofreu influências das transformações antrópicas no espaço agrário entre 1976 e 1997, especialmente do uso da terra. Os autores constataram que a enfermidade esteve associada às lavouras permanentes e temporárias,

Recebido em 26 de junho de 2009 


\section{Gomes et al.}

às pastagens naturais e plantadas e ao efetivo bovino. Taddei et al. (1991) identificaram que os principais rios do estado de São Paulo foram importantes entidades envolvidas na dispersão da enfermidade, pois, ao acompanhá-los, as epidemias tendem a transpassar diversas regiões. Por outro lado, Gomes et al. (2007) constataram que os determinantes inicialmente considerados como aqueles relacionados à enfermidade, principalmente a proximidade aos principais rios, pareciam não estar mais envolvidos na região de São João da Boa Vista, estado de São Paulo. De certa forma, semelhantes resultados já haviam sido descritos por Silva et al. (2001) em relação à influência do tipo de uso e cobertura da terra na distribuição espacial da enfermidade.

É fato que o estado de São Paulo apresenta tipos de usos e cobertura da terra diferentes do início da sua ocupação, ou ainda da década de 80, período em que foram realizados os estudos de Taddei et al. (1991). Os trabalhos de Ehlers (2003) identificaram diminuição do desmatamento e regeneração da mata em diversos municípios paulistas nos períodos entre 1990 e 2000. Em uma parcela do estado, observou-se incremento paulatino das áreas de cana-de-açúcar (Rudorff al., 2004). Já as manchas urbanas aumentaram consideravelmente nas regiões de São José dos Campos e Campinas na década de 90 (Pereira et al., 2005). Essas constatações podem estar influenciando na dinâmica da distribuição da enfermidade há alguns anos.

Dessa forma, novas abordagens e procedimentos metodológicos para o entendimento da distribuição espacial da enfermidade devem ser considerados. Assim, este estudo parte da hipótese de que o perfil de distribuição espacial da enfermidade é moldado pelos mosaicos de uso e cobertura da terra. Tem como objetivo descrever a distribuição espacial da enfermidade e identificar quais tipos de uso e classes de cobertura da terra interferiram no grassamento da raiva bovina na região de maior incidência da enfermidade no estado de São Paulo entre 1992 e 2003.

\section{MATERIAL E MÉTODOS}

Para elaborar este estudo descritivo, desenvolveu-se um banco de dados geográfico (BDG) (Câmara et al., 1996) que contemplou os diagnósticos laboratorialmente positivos de raiva bovina, agregados, respectivamente, a 126 municípios do estado de São Paulo (2184 casos) e a 18 do estado de Minas Gerais (135 casos) entre 1992 e 2003. Cabe ressaltar que os dados dos municípios originados após 1992 ficaram agrupados aos municípios antes de suas emancipações. Dados de altitude e imagens de satélites com suas respectivas classificações foram também inseridos no BDG.

A área de estudo foi formada em grande parte pela região epidêmica paulista (Kotait et al., 1998) e pela área de maior incidência de raiva bovina no estado de São Paulo no período considerado (Gomes, 2008). Esta área possui paisagem e sistemas de produção heterogêneos, cobre o nordeste do estado de São Paulo, com extensão de aproximadamente $50.000 \mathrm{~km}^{2}$ e, para considerar os efeitos de borda, abrangeu os municípios mineiros limítrofes ao estado paulista (Fig. 1).

Para a realização das análises, três camadas foram desenvolvidas e sobrepostas:

Camada 1 (representação espacial da raiva bovina) - A representação espacial da enfermidade foi elaborada de modo que se evidenciasse a densidade de casos da enfermidade, que fosse possível sobrepô-la às outras duas camadas e que ela fosse independente dos limites geográficos impostos pela malha municipal. Para alcançar esses efeitos, uma função kernel quártica (Druck et al., 2004), com raio adaptativo segundo os centroides dos polígonos dos municípios, foi gerada (Câmara et al., 2008). O somatório anual de diagnósticos laboratorialmente positivos de raiva bovina em cada município foi utilizado para a realização da interpolação da função.

Camada 2 (tipos de uso e classes de cobertura da terra) - Quatro imagens de satélite Landsat-TM da metade da série histórica considerada, ou o ano de 1997, foram utilizadas para criar esta camada. A órbita-ponto e as datas de captura das imagens foram: 218-76 (13/08/97); 220-75 $(11 / 08 / 97) ; \quad 219-75 \quad(19 / 07 / 97)$ e $219-76$ (19/07/97). 


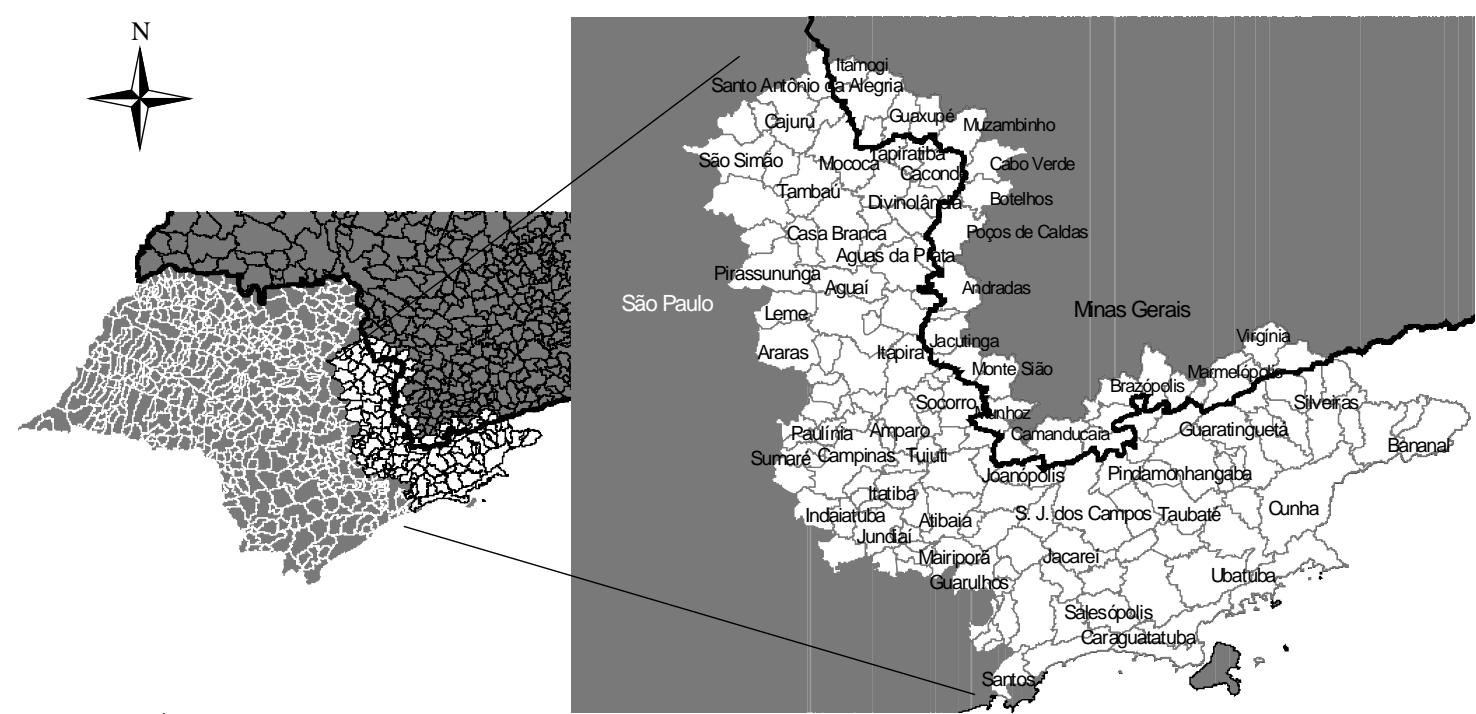

Figura 1. Área de estudo formada por municípios do estado de São Paulo e os limítrofes do estado de Minas Gerais

O conjunto de classes utilizadas para a realização da classificação das imagens foi composto pelas principais feições das paisagens na região. Assim, oito classes de cobertura e tipo de uso da terra foram adotadas: vegetação rasteira (maior parte composta por pastagens), cobertura florestal natural, reflorestamento, corpos de água, lavouras, urbana, cana-de-açúcar e outras (maior parte composta por solo exposto).

As imagens foram registradas (Câmara et al., 1996) tomando-se como referência imagens Landsat/TM (Imagens..., 2003). O sistema de polinômio de primeiro grau e pelo menos seis pontos de controle bem distribuídos georreferenciaram cada imagem. As bandas espectrais utilizadas para a visualização da imagem e a realização da classificação foram $0,60-0,63 \mu \mathrm{m}, 0,63-0,69 \mu \mathrm{m}$ e 0,69-0,76 $\mu \mathrm{m}$, em respectiva composição Red, Green e Blue.

O classificador supervisionado de máxima verossimilhança e Interated Conditional Modes (MaxVer-ICM) pixel-a-pixel (Erthal e Frery, 1993) promoveu a classificação dos pixels das imagens. Uma amostra de 90 pixels em média e bem distribuídos por classe em cada imagem compôs o grupo para treinamento. Uma base de dados, assim como imagens de satélites complementares de outras épocas, auxiliou na identificação dos comportamentos espectrais das entidades geográficas, na sinalização da localização das classes e na indicação de amostras de pixels para treinamento (Gomes, 2008). Uma vez escolhido o grupo de treinamento, elaborou-se a classificação propriamente dita dos demais pixels das imagens. Cumprida a classificação de imagens, realizou-se a edição das classes que se baseou na confrontação de dados com a mesma base de dados. Aspectos mais amplos do desenvolvimento da classificação, verificação e obtenção dos tipos de uso e classes de cobertura da terra podem ser examinados em Gomes (2008).

Os dados de altitude foram obtidos da missão Shuttle Radar Topography Mission (Reprocessing..., 2004) e estavam originalmente agrupados conforme as cartas do território brasileiro na escala 1:250.000. Aquelas utilizadas para preencher a área de estudo foram: SF-23VC, SF-23-YA, SF-23-YC, SF-23-ZA, SF-23VD, SF-23-YB, SF-23-YD, SF-23-ZC. Na sequência, as cartas foram mosaicadas (Câmara et al., 1996), e o dado final compreendeu uma resolução espacial de 90x90 em unidades métricas.

\section{RESULTADOS}

Observou-se, inicialmente, uma difusão bifurcada no Vale do Paraíba entre as várzeas do rio Paraíba do Sul e as bacias do Paraitinga em conjunto com os rios Jacuí e Paraíba do Sul no seu fluxo para a capital paulista. Essa bifurcação 


\section{Gomes et al.}

pareceu ter atendido principalmente a morfologia do relevo e também o desenho da classe cobertura florestal natural localizada no topo das serras do Mar, Mantiqueira e da Quebra Cangalha, que divide o Vale do Paraíba em duas várzeas horizontais. Outro aspecto envolvido foi o de que a difusão da enfermidade se distanciou da várzea plana do Paraíba do Sul, coberta por classes que não são a vegetação rasteira (Fig. 2 e 3A).

A partir de 1995, quando as progressões da enfermidade atingiram a altura do município de Taubaté/SP, onde acaba a divisão das várzeas, as ramificações mesclaram-se com progressões que adentraram a divisa com Minas Gerais no sentido transverso ao Vale do Paraíba (Fig. 2 e 3B). Nessa área, a difusão da enfermidade acompanhou a mancha de baixas altitudes cobertas por pastagens, a qual rompe a Serra da Mantiqueira, para, em seguida, seguir a curvatura do rio Paraíba do Sul ou ser interrompida pela forte presença da conurbação de São José dos Campos. Por fim, ela alcançou a região metropolitana de São Paulo, principalmente o município de Salesópolis/SP e novamente venceu montanhas pelas baixas altitudes (agora a Serra do Mar) para atingir Caraguatatuba/SP (Fig. 2 e 3B).

O número de óbitos de raiva em bovinos aumentou a partir de 1996. As "zonas quentes do kernel” culminaram em 1999 na região entre a divisa de Minas Gerais e o eixo São PauloCampinas. As progressões oriundas do sentido transverso ao Vale do Paraíba uniram-se paulatinamente àquelas que adentraram os municípios de Joanópolis, Vargem, Pedra Bela, Socorro, Águas de Lindoia e Itapira, provavelmente também por manchas de baixas altitudes da divisa de Minas Gerais (Fig. 2 e 3C). No início do deslocamento para o eixo São
Paulo-Campinas, elas acompanharam o terreno em declividade média com manchas descontínuas de lavoura, além dos leitos dos rios Atibaia, Jaguari e Camanducaia. Em seguida, as progressões foram regredindo até atingir as barreiras físicas do eixo São Paulo-Campinas formado pela grande mancha urbana, as Serras da Cantareira e do Japi, respectivamente, ao norte da capital e ao sul de Jundiaí, e a depressão periférica coberta por extensiva cobertura de lavoura e cana-de-açúcar.

As progressões iniciadas em 1999 a partir da divisa estadual no município de Caconde emendaram-se com aquelas da região de Bragança Paulista. Inicialmente, elas acompanharam os leitos dos rios Pardo e JaguariMirim em terreno montanhoso, coberto principalmente por pastagens e manchas de lavoura descontínuas. Porém, no seu terço final, ao atingir áreas mais planas cobertas por lavoura extensiva e cana-de-açúcar, um evidente contorno foi observado, e as progressões desviaram o seu caminho da zona da depressão periférica para as regiões das cuestas cobertas por pastagens (Fig. 2 e 3D).

A integração epidêmica dos estados de São Paulo e Minas Gerais foi bem evidente. Corredores de baixa altitude que contemplam os vales dos rios Sapucaí e Sapucaí-Mirim podem ser ponto de origem de formação de casos que se desdobraram para a região de Bragança Paulista e São José dos Campos, além de outras áreas descritas nas Fig. 3A, 3B, 3C e 3D. A região de Cunha, nas nascentes dos rios Jacuí e Paraitinga, também merece atenção por latência de casos.

Dessa forma, a categorização da enfermidade no período considerado pôde ser dividida de acordo com quatro momentos e áreas dispostas na Fig. 2. 

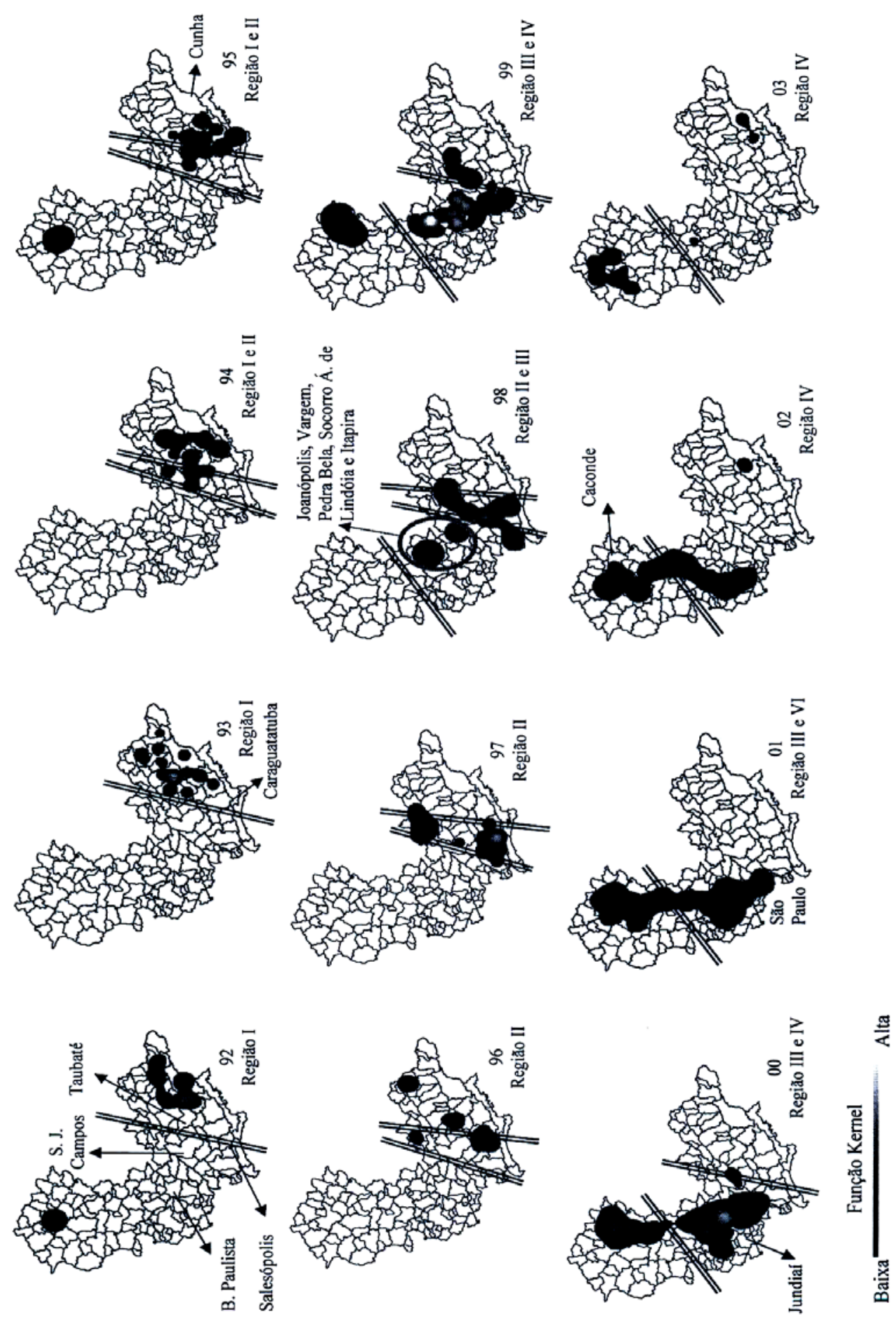

Figura 2. Divisão da área de estudo em quatro regiões segundo progressões da enfermidade caracterizada pela função kernel entre 1992 e 2003. Os valores da função foram padronizados pelo ano de 1999. 


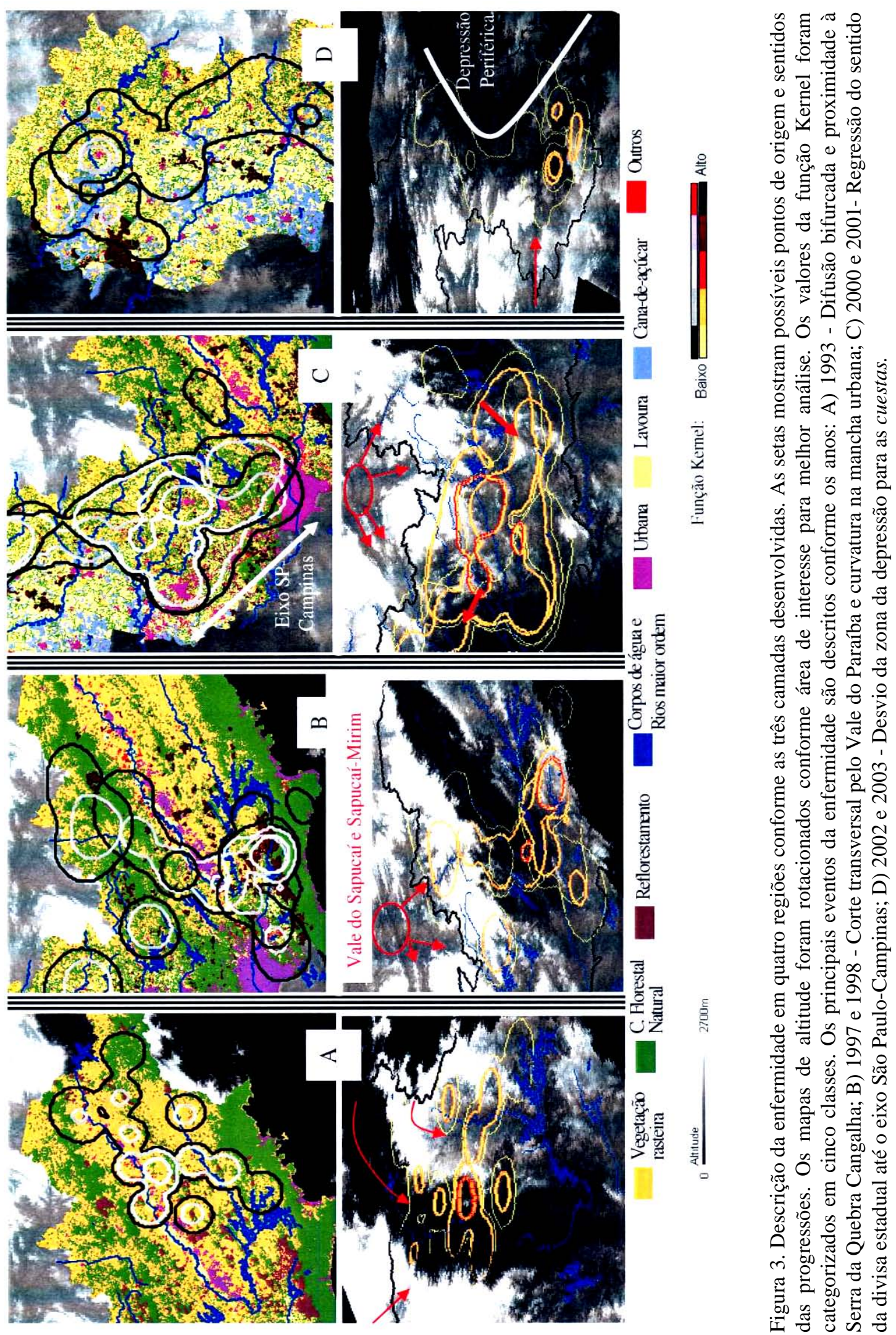




\section{DISCUSSÃO E CONCLUSÕES}

A constatação de que os morcegos Desmodus rotundus se adaptaram a inúmeros abrigos que originalmente não utilizavam pode evidenciar uma proximidade da sua moradia à fonte de alimento (Gomes et al., 2007). Isto pode significar que as epidemias tomam formas difusas as quais se espalhariam entre pastagens que, consequentemente, ficariam moldadas às características da paisagem de uma região. Ratifica-se essa afirmação com a sobreposição da camada 3 sobre a 1 . Tal procedimento demonstrou que a função kernel esteve mais relacionada à classe vegetação rasteira.

Um aspecto revelado pela classificação de imagens foi que a maioria das pastagens está situada em áreas de média declividade. Além de proporcionar áreas mais propícias para os morcegos - Desmodus rotundus tem preferência por regiões com relevo acidentado (Acha e Málaga-Alba, 1988) -, o relevo também deve ser considerado como um condicionador para o tipo de cobertura e o do uso da terra, que por sua vez, atuariam como modeladores espaciais da enfermidade. Grandes áreas de florestas, de forma geral, estão situadas nas regiões de maior declividade; já áreas extensivas de plantações e urbanas situam-se nas partes mais planas (Brasil..., 1965).

A característica da enfermidade na Região I mostrou que as progressões da raiva bovina se aproximaram das várzeas dos rios com ausência de grandes áreas florestais. Essa constatação, de certa forma difere das observações do MAPA (Ministério..., 2005) ao se considerar que regiões declivosas e áreas com florestas são as mais propícias para o grassamento da enfermidade. Todavia, essa contraposição deve ser pautada pelos efeitos de escala de cada trabalho (Gibson et al., 2000) e, também, pelo tipo de várzea de cada rio.

Conforme observado por Taddei et al. (1991), as evidências mostram que os rios deveriam ser considerados como importantes carreadores da enfermidade na Região I, entretanto, ao considerar o tipo de uso e cobertura da terra de cada várzea, outros achados puderam ser observados. Haupt e Rehaag (1925), na primeira epidemia de raiva bovina estudada no Brasil, relataram que partes do Ribeirão de Ilse (estado de Santa Catarina), que possuíam em suas margens menores áreas cultivadas, tinham sofrido mais com a epidemia do que as áreas repletas de plantações. Da mesma forma, pode-se concluir que os mosaicos de uso e cobertura da terra das várzeas dos rios do Vale do Paraíba podem ter interferido na dispersão da enfermidade. Tanto as áreas de lavoura quanto as áreas urbanas que se expandem pela várzea plana do leito do Paraíba do Sul podem ter repelido as progressões para o meio do Vale do Paraíba, ou a Serra da Quebra Cangalha. Contrariamente, as várzeas encaixadas cobertas por pastagens dos rios Paraitinga, parte do Jacuí e Paraíba do Sul (no seu fluxo para a capital paulista) atenderam à formação e manutenção da enfermidade, até atingir a região metropolitana de São Paulo.

As características da enfermidade na Região II podem ser interpretadas de forma semelhante às de Pace (1943), que considerou a Serra do Mar como um grande obstáculo para a difusão da enfermidade do litoral norte para a região leiteira do Vale do Paraíba. $\mathrm{Na}$ análise atual, a enfermidade deve ter sido barrada pelas grandes altitudes da Serra da Mantiqueira na divisa com Minas Gerais. As progressões seguiram para a conurbação de São José dos Campos somente pelas áreas de menor altitude repleta de pastagens, para, em seguida, realizarem uma flexão ao defrontarem a grande mancha urbana. Esse desvio deve ter explicação semelhante à da Região I, ou seja, a mancha urbana da várzea do Paraíba do Sul deve ter provocado a curvatura da enfermidade e, de certa forma, contrapõe os achados de Ferraz et al. (2006), que caracterizaram áreas urbanas como propensas à raiva. Por fim, as progressões atingiram o litoral norte através da Serra do Mar, novamente por áreas de menores altitudes, e também a região metropolitana de São Paulo.

Na Região III, as progressões oriundas da divisa de Minas Gerais migraram para o interior em um formato triangular e acompanharam o relevo de média declividade e o leito dos três principais rios da região. Ao contrário de grande parte do rio Paraíba do Sul, e similarmente aos rios Paraitinga e Jacuí, os três principais rios apresentam várzeas encaixadas. Parece que eles podem fornecer abrigos em um ambiente adequado para os morcegos, da mesma forma como descrito em Taddei et al. (1991). A limitada área plana próxima às várzeas dos rios 


\section{Gomes et al.}

inviabiliza culturas extensivas. Dessa forma, áreas de reflorestamento e lavouras como café, hortifrutis e milho, que são adaptadas ao relevo montanhoso, dispersaram-se por toda a região em blocos descontínuos, entremeada por pastagens (Produção..., 2005). Conforme exposto em Silva et al. (2001), esse tipo de mosaico poderia determinar maior concentração de efetivo bovino e, assim, ocasionar um maior número de casos de raiva bovina.

Tais constatações indicam que os bovinos não seriam "empurrados” para um canto montanhoso com alta concentração de rebanhos, entretanto eles ficariam concentrados em áreas de pastagens, delimitadas por áreas agrícolas descontínuas. Ao acompanharem os leitos dos rios, conforme as hipóteses de Taddei et al. (1991), as progressões tenderiam a regredir, principalmente ao se aproximarem da grande mancha urbana do eixo São Paulo-Campinas e das barreiras físicas das serras da região, que possuem densa cobertura vegetal em seus topos.

Tanto as áreas planas com forte presença de lavoura e cana-de-açúcar quanto, principalmente, a vegetação rasteira em relevo montanhoso devem ter definido as características da enfermidade na Região IV. Delpietro et al. (1992) descreveram que, em lugares com alta população de Desmodus rotundus, ocorre maior disseminação do vírus rábico. Do mesmo modo, um maior número de casos de raiva em bovinos poderia grassar na parte montanhosa repleta de pastagem. De forma inversa, os bovinos localizados em pequenas "ilhas" de pastagem entre o "mar" de vegetação de plantações extensivas e cana-de-açúcar na parte plana poderiam receber proteção das regiões plantadas, desde que o raio de voo dos morcegos infectados fosse menor que a distância entre as "ilhas".

Concluiu-se que a mesma vegetação que protege os bovinos pode promover maior exposição em áreas vizinhas não propícias para culturas extensivas, ou seja, os bovinos praticamente seriam "empurrados" para áreas de relevo acidentado que são as aprazíveis para o Desmodus rotundus (Acha e Málaga-Alba, 1988). Silva et al. (2001) relataram associação entre altos valores de efetivo bovino e raiva, além da constatação de que áreas de lavouras permanentes e temporárias também favoreceriam a enfermidade no estado de Minas Gerais. Os resultados aqui descritos assemelham-se aos desses autores.

Os rios Pardo e Jaguari-Mirim devem ter influenciado as progressões unicamente nas suas partes montanhosas. Os rios são importantes feições geográficas relacionadas à raiva bovina, desde que o tipo de uso e a cobertura da terra das suas várzeas favoreçam a proliferação de morcegos e rebanhos bovinos.

A análise dos eventos evidenciou que há uma forte influência da ação do homem no ambiente. Essa ação não está mais vinculada à transformação de florestas em pasto para a inserção de bovinos (Germano et al., 1992) como aconteceu no passado, mas relacionada ao novo contexto de exploração da terra. Grandes manchas contínuas com mesma classe de cobertura e tipo de uso da terra, como áreas de cana-de-açúcar e urbanas, interferem na história natural da raiva bovina. Novamente, o próprio homem criou condições favoráveis para a adaptação dos morcegos e a proliferação da enfermidade.

\section{AGRADECIMENTOS}

Ao Instituto Pasteur de São Paulo e ao Dr. José Ailton da Silva (UFMG) e Coordenadoria de Defesa Agropecuária do estado de São Paulo, pelo fornecimento de dados. À Paulina Hoffinann pelo auxílio na confecção de mapas. À FAPESP, por financiar este projeto sob No 03-12319-0.

\section{REFERÊNCIA BIBLIOGRÁFICAS}

ACHA, P.N.; MÁLAGA-ALBA, M. Economic losses due to Desmodus rotundus. In: GREENHALL, A. M.; SCHMIDT, U. (Eds). Natural history of vampire bats. Florida: CRC, 1988. p.208-213.

BRASIL. Lei $n^{\circ}$ 4771, de 15 de setembro de 1965. Institui o Novo Código Florestal - Determina a proteção de florestas nativas e define como áreas de preservação permanente. Publicada no DOU de 16 de setembro de 1965.

CÂMARA, G.; SOUZA, R.C.M.; FREITAS, U.M. et al. Integrating remote sensing and GIS by objectoriented data modelling. Comp. Graph., v.20, p.395403, 1996. 
CÂMARA, G.; VINHAS, L.; QUEIROZ, G. et al. TerraLib: An open-source GIS library for large-scale environmental and socio-economic applications. In: HALL, B.; LEAHY, M. (Eds). Open Source Approaches to Spatial Data Handling. Berlin: Springer, 2008. p.247-271.

CONTROLE da raiva dos herbívoros. Brasília: MAPA, 2005. 104p.

DELPIETRO, H.A.; MARCHEVSKY, N.; SIMONETTI, E. Relative population densities and predation of the common vampire bat (Desmodus rotundus) in natural and cattle-raising areas in northeast Argentina. Prev. Vet. Med., v.14, p.13-20, 1992.

DRUCK, S.; CARVALHO, M.S.; CÂMARA, G. et al. Análise espacial de dados geográficos. Brasília: Embrapa, 2004. 209p. Disponível em: <http://www.dpi.inpe.br/gilberto/livro/analise/> Acessado em: 22 mar. 2004.

EHLERS, E.M. Determinantes da recuperação da Mata Atlântica no estado de São Paulo. 2003. 351f. Tese (Doutorado) - Universidade de São Paulo, São Paulo.

ERTHAL, G.J.; FRERY, A.C. Segmentação de imagens multiespectrais pelo algoritmo Icm: Integração ao ambiente spring. In: SIMPÓSIO BRASILEIRO DE COMPUTAÇÃO GRÁFICA E PROCESSAMENTO DE IMAGENS, 6., 1993, Recife Anais...Recife. SIBRAPI, 1993. p.33-36.

FERRAZ, C.; ACHKAR, M.S., KOTAIT, I. Primer relato de murciélago hematófago (Desmodus rotundus) infectado por el vírus de la rabia, encontrado em um centro urbano, SP, Brasil. In: RITA - RABIES IN THE AMÉRICAS, 17., 2006, Brasília. Anais... Brasília: Ministério da Saúde, 2006. p.56.

GERMANO, P.M.L.; GERMANO, M.I.S.; MIGUEL, O. et al. O papel dos morcegos hematófagos na cadeia de transmissão da raiva silvestre. Comun. Cientif. Fac. Med. Vet. Zootec. USP., v.1, p.21-25, 1992.

GIBSON, C.; OSTROM, E.; AHN, T.K. The concept of scale and the human dimensions of global change: a survey. Eco. Econ., v.32, p.217-239, 2000.

GOMES, M.N.; MONTEIRO, A.M.V.; NOGUEIRA, V.S. et al. Áreas propícias para o ataque de morcegos hematófagos Desmodus rotundus em bovinos na região de São João da Boa Vista, estado de São Paulo. Pesq. Vet. Bras., v.27, p.307-313, 2007.

GOMES, M.N. Padrões espaciais da raiva bovina e seus determinantes no estado de São Paulo entre 1992 e 2003. 2008. 277f. Tese (Doutorado) - Instituto Nacional de Pesquisas Espaciais, São Paulo.
HAUPT, H.; REHAAG, H. Raiva epizoótica nos rebanhos de Santa Catarina, sul do Brasil, transmitida por morcegos. Bol. Soc. Bras. Med. Vet., v.2, p.17-47, 1925.

IMAGENS do estado de São Paulo. Imagens de satélite. Landsat-TM- Composição RGB, Bandas 3, 4 e 5, Base 218/Ponto: 76; Base 220/Ponto: 75; Base 219/Ponto: 76; Base 219/Ponto: 76. Maryland: Global Land Cover Facility, 2003. Disponível em: $<$ http://glcf.umiacs.umd.edu/index.shtml $>$. Acessado em 20 dez. 2005.

KOTAIT, I.; GONÇALVES, C.A; PERES, N.F. et al. Controle da raiva dos herbívoros. São Paulo: Instituto Pasteur, 1998. 15p.

MAYEN, F. Hematophagous bats in Brazil, their role in rabies transmission, impact on public health, livestock industry: an alternative to an indiscriminate reduction of bat populations. J. Vet. Med. Series B, v.50, p.469-472, 2003.

PACE, R. Algo sobre a raiva dos herbívoros no Brasil. Bol. Soc. Bras. Med. Vet., v.12, p.99-107, 1943.

PEREIRA, N.M.; GONÇALVES, C.D.A.B.; SOUZA, I.M. et al. Uso de imagens de satélite como subsídio ao estudo do processo de urbanização. São José dos Campos: INPE, 2005. 39p.

PRODUÇÃO agrícola municipal. Rio de Janeiro: IBGE, $2005 . \quad$ Disponível em: $<$ http://www.sidra.ibge.gov.br/ Acessado em: 12 dez. 2005.

REPROCESSING by the GLCF. $(1,3,30)$ Arc Second SRTM Elevation, Reprocessed to GeoTIFF. Version 1.0. College Park, Maryland: The Global Land Cover Facility, 2004

RUDORFF, B.F.T.; SUGAWARA, L.M.B.; CÂNDIDO, A.X. et al. Estimativa de área plantada com cana-de-açúcar em municípios do estado de São Paulo por meio de imagens de satélites e técnicas de geoprocessamento: ano safra 2003/2004. São José dos Campos: INPE, 2004. 48p.

SILVA, J.A.; MOREIRA, E.C.; HADDAD, J.P.A. et al. Uso da terra como determinante da distribuição da raiva bovina em Minas Gerais, Brasil. Arq. Bras. Med. Vet. Zootec., v.53, p.273-283, 2001.

TADDEI, A.V.; GONÇALVES, C.A.; PEDRO, W.A. et al. Distribuição do morcego vampiro Desmodus rotundus no estado de São Paulo e a raiva dos animais domésticos. Campinas: Coordenadoria de Assistência Técnica Integral, 1991. 107p. 